Agarwal SK, Gourh P, Shete S, Paz G, Divecha D, Reveille JD, Assassi S, Tan FK, Mayes MD, Arnett FC. Association of interleukin 23 receptor polymorphisms with anti-topoisomerase-I positivity and pulmonary hypertension in systemic sclerosis. J Rheumatol 2009;36:2715-23. Support for the study should be given credit as follows. Funding for part of this study was obtained from the DOD (U.S. Department of Defense) Congressionally Directed Medical Research Program (CDMRP) grant PR064251. We regret the error.

doi:10.3899/jrheum.090421C1 


\title{
Association of Interleukin 23 Receptor Polymorphisms with Anti-Topoisomerase-I Positivity and Pulmonary Hypertension in Systemic Sclerosis
}

\author{
SANDEEP K. AGARWAL, PRAVITT GOURH, SANJAY SHETE, GENE PAZ, DIPAL DIVECHA, JOHN D. REVEILLE, \\ SHERVIN ASSASSI, FILEMON K. TAN, MAUREEN D. MAYES, and FRANK C. ARNETT
}

\begin{abstract}
Objective. IL23R has been identified as a susceptibility gene for development of multiple autoimmune diseases. We investigated the possible association of $I L 23 R$ with systemic sclerosis (SSc), an autoimmune disease that leads to the development of cutaneous and visceral fibrosis.

Methods. We tested 9 single-nucleotide polymorphisms (SNP) in IL23R for association with SSc in a cohort of 1402 SSc cases and 1038 controls. IL23R SNP tested were previously identified as SNP showing associations with inflammatory bowel disease.

Results. Case-control comparisons revealed no statistically significant differences between patients and healthy controls with any of the IL23R polymorphisms. Analyses of subsets of SSc patients showed that rs11209026 (Arg381Gln variant) was associated with anti-topoisomerase I antibody (ATA)-positive SSc $(\mathrm{p}=0.001)$ ) and $\mathrm{rs} 11465804 \mathrm{SNP}$ was associated with diffuse and ATA-positive SSc $(p=0.0001, p=0.0026$, respectively). These associations remained significant after accounting for multiple comparisons using the false discovery rate method. Wild-type genotype at both rs11209026 and rs11465804 showed significant protection against the presence of pulmonary hypertension (PHT). ( $\mathrm{p}=3 \times 10^{-5}, \mathrm{p}=1 \times 10^{-5}$, respectively).

Conclusion. Polymorphisms in IL23R are associated with susceptibility to ATA-positive SSc and protective against development of PHT in patients with SSc. (First Release Nov 15 2009; J Rheumatol 2009;36:2715-23; doi:10.3899/jrheum.090421)
\end{abstract}

Key Indexing Terms: SYSTEMIC SCLEROSIS POLYMORPHISM

\begin{tabular}{ccc}
\multicolumn{2}{c}{ SCLERODERMA } & $I L 23 R$ \\
AUTOANTIBODIES & PULMONARY HYPERTENSION
\end{tabular}

From the Division of Rheumatology and Clinical Immunogenetics, Department of Internal Medicine, University of Texas Health Science Center at Houston (UTHSC-H); and Department of Epidemiology, Division of Cancer Prevention and Population Sciences, The University of Texas, MD Anderson Cancer Center, Houston, Texas, USA.

Supported by the Scleroderma Foundation New Investigator Award (Dr. Agarwal), NIH/NIAMS-K08AR054404 (Dr. Agarwal), NIH/NIAMS Center of Research Translation in Scleroderma (P50AR054144) (Drs. Arnett and Tan), the NIH/NIAMS Scleroderma Family Registry and DNA Repository (N01-AR-0-2251) (Dr. Mayes), and UTHSC-H Center for Clinical and Translational Sciences (Houston CTSA Program) (NIH/NCRR 3UL1RR024148) (Drs. Arnett and Agarwal).

S.K. Agarwal, MD, PhD; P. Gourh, MD, Division of Rheumatology and Clinical Immunogenetics, Department of Internal Medicine, University of Texas Health Science Center at Houston; S. Shete, PhD, Department of Epidemiology, Division of Cancer Prevention and Population Sciences, The University of Texas, MD Anderson Cancer Center; G. Paz, BA; D. Divecha, BA; J.D. Reveille, MS; S. Assassi, MS; F.K. Tan, MD, PhD; M.D. Mayes, MD, MPH; F.C. Arnett, MD, Division of Rheumatology and Clinical Immunogenetics, Department of Internal Medicine, University of Texas Health Science Center at Houston.

Dr. Agarwal and Dr. Gourh contributed equally to this report.

Address correspondence to Dr. S.K. Agarwal, Division of Rheumatology and Clinical Immunogenetics, University of Texas Health Science Center, 6431 Fannin St., MSB 5.278, Houston, TX 77030.

E-mail: Sandeep.K.Agarwal@uth.tmc.edu

Accepted for publication July 16, 2009.
Systemic sclerosis (scleroderma, SSc) is a chronic multisystem disease clinically characterized by autoimmunity leading to progressive fibrosis in the skin and internal organs ${ }^{1}$. Pathologically, SSc exhibits 3 cardinal features: inflammation and autoimmunity, vasculopathy, and excessive extracellular matrix production and deposition ${ }^{1}$. It remains to be determined how the disease process is triggered, but current models indicate immune dysregulation as a central process in the pathogenesis of SSc.

Skin biopsies of early scleroderma skin demonstrate perivascular infiltrates of mononuclear inflammatory cells, including $\mathrm{CD} 4+\mathrm{T}$ cells, which produce cytokines and chemokines that induce tissue damage, promote fibrosis, and recruit additional inflammatory cells ${ }^{2}$. Several subsets of effector CD4+ T cells have been identified based on their distinct cytokine profiles ${ }^{3}$. In the presence of interleukin 12 (IL-12), naive CD4+ T cells differentiate into Th1 cells characterized by the production of interferon- $\gamma(\text { IFN- } \gamma)^{4}$. In the presence of IL-4, naive CD4+ T cells differentiate into Th 2 cells characterized by the production of IL- 4 , IL- 5 , and IL-13 ${ }^{4}$. A novel subset of T cells, Th17, characterized by the 
production of IL-17, has been identified ${ }^{5}$. Th17 cells differentiate from naive $\mathrm{CD} 4+\mathrm{T}$ cells upon $\mathrm{T}$ cell receptor activation in the presence of IL- 6 and transforming growth factor $\beta(\text { TGF- } \beta)^{6,7}$.

Current models suggest Th17 cells as key mediators in the pathogenesis of a variety of autoimmune diseases, such as rheumatoid arthritis, inflammatory bowel disease (IBD), psoriasis, and ankylosing spondylitis (AS) ${ }^{8}$. IL-23 and the IL-23 receptor have been implicated in the development of autoimmune diseases such as multiple sclerosis ${ }^{9}$. While IL-23 is not required for Th17 differentiation, it is an important cytokine that promotes expansion of the Th17 population by inducing proliferation of Th17 cells ${ }^{10}$. IL-23 signals through the heterodimeric IL-23 receptor, composed of the IL-12Rß1 chain and a unique subunit called IL-23R 9 . Genome-wide association studies have demonstrated that single-nucleotide polymorphisms (SNP) in the $I L 23 R$ gene confer a significant risk for development of multiple autoimmune diseases including IBD, psoriasis, and $A S^{11-16}$. These studies implicate IL-23 and Th17 cells in the immune pathogenesis of these diseases.

It has been hypothesized that Th17 cells might play a role in the pathogenesis of SSc. Indeed, plasma concentrations of IL-17 and IL-23 have been reported to be elevated in Japanese SSc patients from 2 cohorts ${ }^{17,18}$. Further, peripheral blood $\mathrm{T}$ cells from patients with SSc have been reported to produce increased levels of IL-1 $7^{17}$. These studies point to an increase in Th17 cytokine activity in SSc. Given the potential role of Th17 cells in the immunopathogenesis of $\mathrm{SSc}$, we investigated if polymorphisms in IL23R are associated with SSc susceptibility and clinical phenotypes in a large cohort of North American SSc patients compared to healthy controls.

\section{MATERIALS AND METHODS}

SSc patients and controls. In total, 1402 SSc patients and 1038 healthy control subjects from the Scleroderma Family Registry and DNA Repository ${ }^{19}$ and the University of Texas Rheumatology Division ${ }^{20}$, dating from 1986 to present, including the Genetics versus Environment in Scleroderma Outcomes Study (GENISOS) ${ }^{21}$ formed the study cohort. All SSc patients fulfilled American College of Rheumatology (ACR; formerly American Rheumatism Association) preliminary criteria for disease classification ${ }^{22}$ (n $=1122,80 \%$ ) or had at least 3 of the 5 CREST features (calcinosis, Raynaud's phenomenon, esophageal dysfunction, sclerodactyly, and telangiectasias) $(\mathrm{n}=280,20 \%)^{23,24}$.

Clinical data were obtained from the database. Ethnicity was selfdefined by the cases and controls. Patients were classified as having limited or diffuse cutaneous SSc disease according to published criteria ${ }^{25}$. Clinical data also were obtained from the database to determine visceral involvement, including fibrosing alveolitis, pulmonary hypertension (PHT), and scleroderma renal crisis. Fibrosing alveolitis was defined as the presence of typical findings on chest high-resolution computerized tomography $(\mathrm{CT})$, regular chest $\mathrm{CT}$ or radiograph, or restrictive pattern on pulmonary function testing. PHT was defined as estimated peak right-ventricular systolic pressure $\geq 40 \mathrm{~mm} \mathrm{Hg}$ on echocardiography or pulmonary arterial systolic pressure $\geq 40 \mathrm{~mm} \mathrm{Hg}$ by right-heart catheterization. Scleroderma renal crisis was characterized by the presence of new-onset accelerated systemic hypertension with evidence of renal impairment.
All subjects provided written informed consent and the study was approved by the Committee for the Protection of Human Subjects of The University of Texas Health Science Center at Houston.

Autoantibody analysis. All SSc patients were tested for antinuclear antibodies using indirect immunofluorescence (IIF) and HEp-2 cells as antigen substrate (Antibodies Inc., Davis, CA, USA). Anticentromere antibodies (ACA) were determined by their distinctive IIF pattern on HEp- 2 cells ${ }^{26}$. Autoantibodies to topoisomerase I (ATA) were determined by passive immunodiffusion (Inova Diagnostics, San Diego, CA, USA). Anti-RNA polymerase III antibodies (ARA) were determined by enzyme-linked immunoassay (MBL Co. Ltd., Nagoya, Japan). For ARA, the cutoff was defined as 2.5 standard deviations above the mean of 40 healthy controls.

SNP selection and genotyping. SNP in the IL23R gene were selected based on $I L 23 R$ variants identified in 2 independent genome-wide association studies in $\mathrm{IBD}^{11,12}$. The following $I L 23 R$ SNP were tested: intronic SNP rs1884444, rs1004819, rs11805303, rs7530511, rs10489629, rs11465804, and rs1343151; exonic 3'-untranslated region SNP rs10889677; and nonsynonymous SNP rs11209026 (Arg381Gly).

Genomic DNA was extracted from peripheral blood with the PureGene genomic DNA isolation kit (Gentra Systems, Minneapolis, MN, USA). The SNP were genotyped using an ABI-TaqMan SNP genotyping assay (Applied Biosystems ABI, Foster City, CA, USA). The ABI 7900HT realtime thermocycler was used to perform the plate reading. Automated allele calling was performed by allelic discrimination plots using SDS 2.3 software (ABI). Multiple positive (CEPH samples) and negative controls were used in each genotyping assay and allele calls were verified with HAPMAP data for validation.

Statistical analysis. Statistical analyses were performed using SAS 9.1.3 (SAS Institute Inc., Cary, NC, USA). Hardy-Weinberg equilibrium testing was performed using the exact test. Allelic and genotypic associations were calculated using standard Pearson's chi-square test or, when appropriate, Fisher's exact test. To account for multiple comparisons, we used a false discovery rate approach ${ }^{27}$, less conservative than a traditional Bonferroni correction. We used alpha $=0.05$ level of significance and accounted for 135 potential multiple comparisons that were performed. These comparisons include each of the 9 SNP tested for different ethnic groups and different subtypes of SSc. Using these values for alpha and the number of tests performed, a point-wise significance of 0.0051 is considered significant accounting for multiple comparisons. Measures of pairwise linkage disequilibrium were determined using Haploview (Whitehead Institute for Biomedical Research, Cambridge, MA, USA).

\section{RESULTS}

Demographic data. A candidate gene association study was conducted using SSc patients and healthy controls from the Scleroderma Family Registry and DNA Repository combined with subjects evaluated at the University of Texas Houston Rheumatology Division. Clinical and serological information of patients are presented in Table 1. In total, 1402 SSc patients and 1038 healthy controls were enrolled for study belonging to Caucasian, African American, and Hispanic ethnic groups. Seven hundred thirty patients had diffuse scleroderma and 595 had limited scleroderma. Of 1402 patients, 341 (24\%) were positive for the ACA, 256 (18\%) for ATA, and 261 (19\%) for the ARA.

Linkage disequilibrium and haplotype block structure of IL23R gene healthy controls. Pairwise linkage disequilibrium was calculated by both D' and $\mathrm{r}^{2}$ for the 9 IL23R SNP typed in Caucasian, African American, and Hispanic controls (Figure 1). The IL23R SNPs- rs11209026-rs11465804 
Table 1. Clinical and serologic characteristics of patients with systemic sclerosis (SSc)* and healthy controls. Data are $\mathrm{n}(\%)$

\begin{tabular}{lccc}
\hline Characteristic & Caucasian & African American & Hispanic \\
\hline Controls & $698^{*}$ & $201^{*}$ & 139 \\
Female & $334(50.8)$ & $142(71.0)$ & $80(57.6)$ \\
Male & $323(49.2)$ & $58(29.0)$ & $59(42.4)$ \\
SSc & 1059 & 177 & 166 \\
Female & $935(88.3)$ & $151(85.3)$ & $148(89.2)$ \\
Male & $124(11.7)$ & $26(14.7)$ & $18(10.8)$ \\
Skin involvement & 1004 & 164 & 157 \\
Limited SSc & $611(60.9)$ & $53(32.3)$ & $66(42.0)$ \\
Diffuse SSc & $393(39.1)$ & $111(67.7)$ & $91(58.0)$ \\
Antibodies & 667 & 86 & 105 \\
Anticentromere & $300(45.0)$ & $12(14.0)$ & $29(27.6)$ \\
Anti-topoisomerase I & $174(26.1)$ & $43(50.0)$ & $39(37.2)$ \\
Anti-RNA polymerase III & $193(28.9)$ & $31(36.0)$ & $37(35.2)$ \\
\hline
\end{tabular}

* Missing gender information on 41 white and 1 black samples.

and rs1004819-rs11805303 showed tight LD in the Caucasian population $(\mathrm{r} 2>0.90)$. The IL23R SNP rs1004819-rs11805303 were in complete linkage disequilibrium in the African American control population and rs11209026-rs11465804 were in complete linkage disequilibrium in the Hispanic control population $\left(\mathrm{r}^{2}=1.0\right)$.

IL-23R polymorphisms and association with $S S c$. A total of 9 SNP in the $I L 23 R$ gene were genotyped in our cohorts. All SNP studied in the IL23R gene were in Hardy-Weinberg equilibrium in Caucasian, African American, and Hispanic controls (Table 2). Allelic frequencies of the polymorphisms were similar between sexes in cases and controls. Case-control comparisons for genotypes using the chi-square test did not reach statistical significance in the Caucasian population for all the $9 I L 23 R$ SNP (Table 3). In African Americans, there was a genotypic association of the rs1884444 SNP with SSc susceptibility $(\mathrm{p}=0.004)$. In Hispanics, a minor allelic association with SSc susceptibility was observed with the rs1343151 SNP ( $p=0.047)$, but this was not significant after accounting for multiple comparisons.

IL-23R polymorphisms and association with SSc subsets. $\mathrm{SSc}$ is a clinically heterogeneous disease, divided into 2 main subsets based on the extent of cutaneous involvement: limited and diffuse ${ }^{25}$. The presence of SSc-associated autoantibodies such as ACA, ATA, and ARA has been shown to be associated with distinct clinical subsets characterized by extent of cutaneous involvement and pattern of organ involvement, such as PHT, pulmonary fibrosis, or SSc renal crisis, respectively ${ }^{28}$. Several studies have recently shown that certain genetic polymorphisms may have stronger associations with particular phenotypic subsets $^{29,30}$. Therefore, we compared the frequency of $I L 23 R$ SNP within the clinical and autoantibody subsets of SSc in Caucasians

Of the 9 IL23R SNP, 2 (rs11209026 and rs11465804) were associated with susceptibility to specific subsets of
SSc in Caucasians (Table 4a, 4b). Genotypic comparison revealed that GG homozygosity at the IL23R SNP rs11209026 (Arg381Gln) was found more frequently in patients with diffuse SSc compared to controls (Table 4a), although this did not remain significant after accounting for multiple comparisons $(\mathrm{p}=0.027)$. Using the SSc-associated autoantibodies to subcategorize SSc patients, we found a significant association of the GG genotype at the IL23R SNP rs11209026 in ATA-positive patients relative to controls $(\mathrm{p}=0.001)$, which was significant using the point-wise threshold of 0.0051 accounting for multiple comparisons. The IL23R SNP rs11209026 was more associated with ATA-positive SSc patients relative to ATA-negative SSc patients $(\mathrm{p}=0.007)$, but this did not remain significant after correcting for multiple comparisons. The association of rs11209026 with ATA-positive SSc was also observed after deleting patients who had only 3 of 5 CREST features but did not meet the ACR preliminary criteria for $\operatorname{SSc}^{22}(\mathrm{p}=$ $0.0003)$. No associations were found between limited scleroderma and the ACA-positive or ARA-positive patients. Haplotype analyses was performed but did not show any additional associations with susceptibility to ATA-positive SSc. No associations of IL23R SNP rs11209026 with subsets of SSc were observed in African American or Hispanic SSc patients (data not shown).

Similar associations were observed with the IL23R SNP rs11465804 (Table 4b). Genotypic comparison demonstrated that TT homozygosity at the IL23R SNP rs11465804 was more frequent in patients with diffuse SSc compared to controls (Table 4a), and this remained significant after accounting for multiple comparisons $(\mathrm{p}=0.002)$. Using SSc-associated autoantibodies to subcategorize SSc patients, we observed a significant association of the TT genotype at the IL23R SNP rs11465804 in ATA-positive patients relative to controls $(\mathrm{p}=0.0001)$ and relative to ATA-negative SSc patients $(p=0.0026)$, both of which remained significant Personal non-commercial use only. The Journal of Rheumatology Copyright (c) 2009. All rights reserved. 


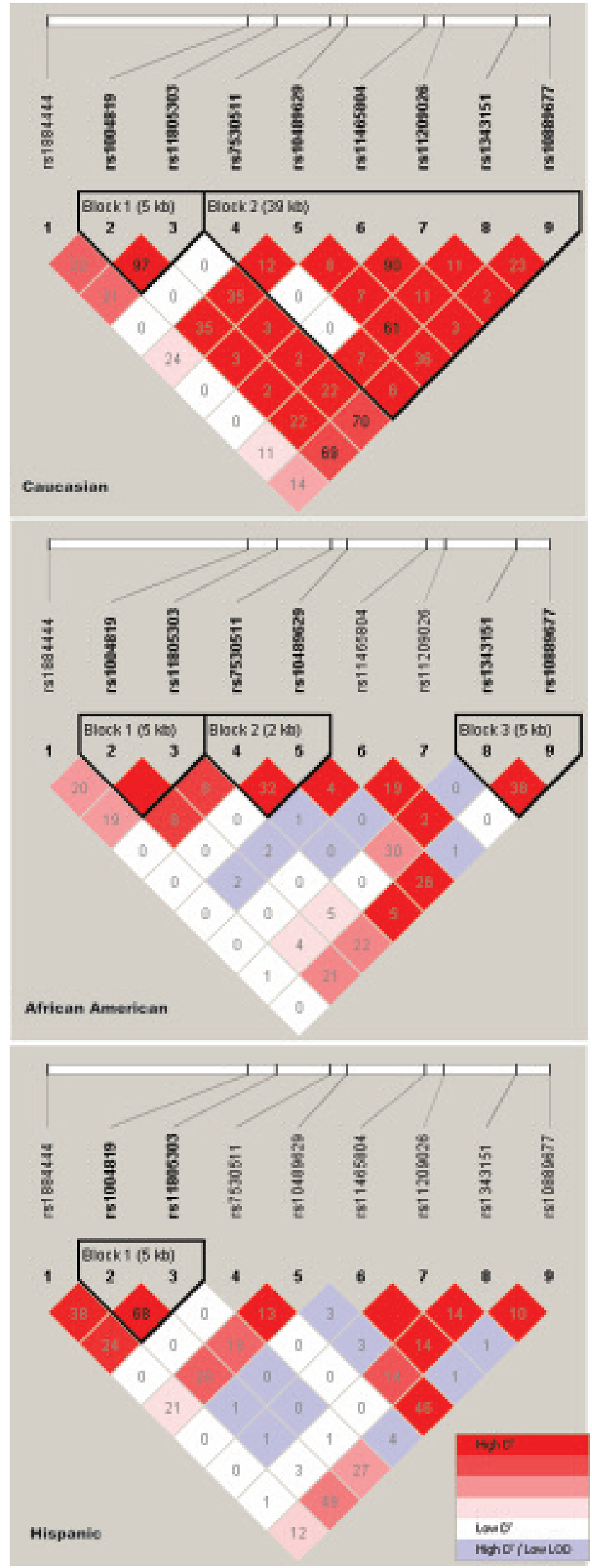

after accounting for multiple comparisons using a pointwise threshold of 0.0051 . The association of rs 11465804 with ATA-positive SSc was also observed after deleting patients who had only 3 of 5 CREST features but did not meet the ACR criteria for SSc $(\mathrm{p}<0.0001)$. No associations were found between limited scleroderma and ACA-positive or ARA-positive patients. No associations of IL23R SNP rs 11465804 with subsets of SSc were observed in African American or Hispanic SSc patients (data not shown).

Together these data demonstrate that even after controlling for multiple comparisons, there was a significant association of 2 IL23R polymorphisms (rs11209026 and rs11465804) with susceptibility to ATA-positive SSc in North American Caucasians.

Association of IL23R polymorphisms with visceral involvement of SSc. Additional analyses were performed to determine if the 2 susceptibility IL23R SNP (rs11209026 and rs 11465804) were associated with visceral involvement of SSc, such as fibrosing alveolitis, PHT, or SSc renal crisis (Table 5a, 5b). Interestingly, the major allele at both IL23R SNP (rs11209026 and rs11465804) that was associated with ATA-positive SSc demonstrated statistically significantly decreased frequency with the presence of PHT (by genotypic analyses, $\mathrm{p}=3 \times 10^{-5}$ for rs 11209026 , and $\mathrm{p}=1 \times 10^{-5}$ for rs11465804; by allelic analyses, $\mathrm{p}=0.005$ for rs 11209026 , and $p=0.001$ for $r$ 11465804). These associations remained significant after correcting for multiple comparisons using the false discovery rate method. The major allele frequencies of these 2 SNP (G at rs11209026 and T at rs11465804) were decreased in SSc cases with PHT, compared to SSc cases without PHT. The protective association of the IL23R polymorphisms was found to be independent of age, sex, and the presence of SSc-associated autoantibodies including ACA, ATA, and ARA by logistic regression (data not shown). Thus, the IL23R SNP rs11209026 and rs11465804 were protective with regard to development of PHT in SSc. Chi-square analyses showed no associations with fibrosing alveolitis or SSc renal crisis. Together, these data show that the wild-type genotype for the 2 IL23R SNP is negatively associated with development of PHT in SSc.

\section{DISCUSSION}

We demonstrated that $I L 23 R$ polymorphisms are associated with diffuse SSc and ATA-positive SSc, but show no associations with limited SSc or ACA-positive or ARA-positive SSc. In addition to being a susceptibility factor for the devel-

Figure 1. Linkage disequilibrium (LD) and haplotype structure of $I L 23 R$ gene. LD between SNP across the IL23R gene region is shown within healthy controls. Blocks connecting pairs of SNP are shaded according to the strength of the LD between the SNP, from 0.0 (white) to 1.0 (bright red), as measured by the disequilibrium coefficient D'. The blue blocks indicate pairs of markers for which $\mathrm{D}^{\prime}$ is equal to 1.0 , but the LOD score is less than 2.0. As an additional measure of strength of $\mathrm{LD}, \mathrm{r}^{2}$ values are given as numerical values within each box. 
Table 2. Hardy-Weinberg equilibrium of $I L 23 R$ gene single-nucleotide polymorphisms (SNP) in healthy controls.

\begin{tabular}{lccccc}
\hline IL23R & IL23R SNP & Position, bp & Caucasian & $\begin{array}{c}\mathrm{p} \text {, Chi-square } \\
\text { African American }\end{array}$ & Hispanic \\
\hline 1 & rs1884444 & 67406400 & 0.59 & 0.07 & 0.09 \\
2 & rs1004819 & 67442801 & 0.67 & 0.58 & 0.93 \\
3 & rs11805303 & 67448104 & 0.70 & 0.46 & 0.83 \\
4 & rs7530511 & 67457975 & 0.99 & 0.62 & 0.76 \\
5 & rs10489629 & 67460937 & 0.56 & 0.74 & 0.52 \\
6 & rs11465804 & 67475114 & 0.24 & 0.46 & 0.66 \\
7 & rs11209026 & 67478546 & 0.29 & 0.89 & 0.66 \\
8 & rs1343151 & 67491717 & 0.48 & 0.89 & 0.66 \\
9 & rs10889677 & 67497708 & 0.95 & 0.23 & 0.53 \\
\hline
\end{tabular}

Table 3. Distribution of the IL23R genotype in SSc and controls.

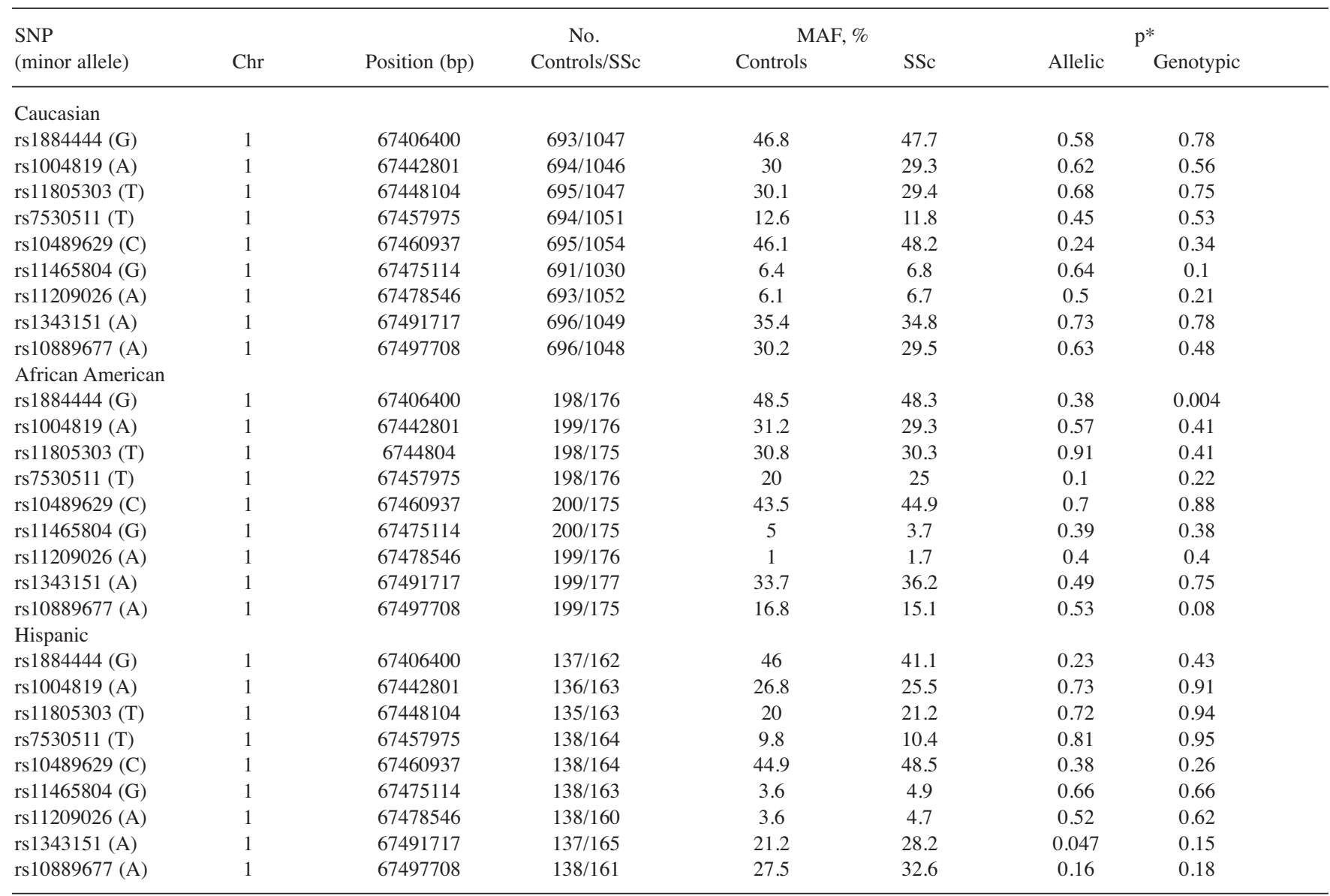

$* \mathrm{p}$ values considered significant after correcting for multiple comparisons using the false discovery method and point-wise significance $=0.0051$. SNP: single-nucleotide polymorphism; Chr: chromosome; MAF: minor allele frequency.

opment of specific subsets of SSc, IL23R SNP exert a protective effect for the development of PHT. These data add to the growing list of immune-associated genes that are associated with susceptibility to SSc that includes MHC class II, PTPN22, AIF1, and IRF5 and thus position immune dysregulation as being pivotal to the pathogenesis of $\mathrm{SSc}^{29-32}$.
SSc is a heterogeneous autoimmune disease that is clinically categorized based on the degree of cutaneous involvement ${ }^{1,25}$. Limited SSc is defined by skin thickening in areas distal to the elbows and knees. In contrast, diffuse SSc is defined by the presence of skin thickening proximal and distal to the elbow and knees. The SSc-associated autoantibod- 
Table 4A. Distribution of the IL23R SNP rs11209026 genotype in North American Caucasian patients with SSc and healthy controls.

\begin{tabular}{lccccc}
\hline & \multicolumn{5}{c}{ Genotypic Comparison } \\
& No. & AA & AG & GG & $\mathrm{p}^{\dagger}$ \\
& & & $\%$ & & \\
\hline Controls & 693 & 0.1 & 12.0 & 87.9 & \\
Patients with SSc & 1052 & 0.8 & 11.9 & 87.4 & 0.21 \\
Limited & 608 & 0.5 & 12.8 & 86.7 & 0.47 \\
Diffuse & 389 & 1.3 & 9.5 & 89.2 & 0.027 \\
Antibodies & & & & & \\
Anticentromere & 298 & 0.7 & 12.4 & 86.9 & 0.37 \\
Anti-topoisomerase I & 173 & 2.3 & 7.5 & 90.2 & 0.001 \\
Anti-RNA polymerase III & 191 & 0.5 & 12.6 & 86.9 & 0.60 \\
ATA+ vs ATA- $\dagger$ & 170 & 2.3 & 7.5 & 90.2 & 0.007 \\
& 852 & 0.5 & 12.6 & 86.9 & \\
\hline
\end{tabular}

${ }^{\dagger} \mathrm{p}$ values considered significant after correcting for multiple comparisons using the false discovery method and point-wise significance $=0.0051{ }^{\dagger \dagger}$ Controls used as reference for all comparisons except this one.

Table 4B. Distribution of the IL23R SNP rs11465804 genotype in North American Caucasian patients with SSc and healthy controls.

\begin{tabular}{lccccc}
\hline & \multicolumn{5}{c}{ Genotypic Comparison } \\
& No. & GG & GT & TT & $\mathrm{p}^{\dagger}$ \\
& & & $\%$ & \\
\hline Controls & 691 & 0.1 & 12.6 & 87.3 & \\
Patient with SSc & 1030 & 1.0 & 11.7 & 87.3 & 0.10 \\
Limited & 593 & 0.5 & 12.8 & 86.7 & 0.51 \\
Diffuse & 383 & 1.8 & 9.1 & 89.0 & 0.002 \\
Antibodies & & & & & \\
Anticentromere & 292 & 0.7 & 13.0 & 86.3 & 0.36 \\
Anti-topoisomerase I & 170 & 2.9 & 7.1 & 90.0 & 0.0001 \\
Anti-RNA polymerase III & 186 & 1.1 & 11.8 & 87.1 & 0.15 \\
ATA+ vs ATA- ${ }^{\dagger}$ & 170 & 2.9 & 7.1 & 90.0 & 0.0026 \\
& 852 & 0.6 & 12.6 & 86.9 & \\
\hline
\end{tabular}

\footnotetext{
${ }^{\dagger} \mathrm{p}$ values considered significant after correcting for multiple comparisons using the false discovery method and point-wise significance $=0.0051 .{ }^{\dagger \dagger}$ Controls used as reference for all comparisons except this one.
}

ies such as ACA, ATA, and ARA have also been used to categorize patients ${ }^{28,33}$. The presence of these antibodies is also associated with the degree of cutaneous involvement as well as visceral involvement. For example, ACA is found almost exclusively in patients with limited SSc and helps identify patients at higher risk for development of PHT and lower risk for development of interstitial lung disease ${ }^{33}$. In contrast, presence of ATA is often associated with diffuse SSc as well as a higher risk of interstitial lung disease and lower risk of PHT $^{33}$. The association of $I L 23 R$ SNP with risk of developing diffuse SSc and ATA-positive SSc is consistent with these observations. Accordingly, we hypothesized that $I L 23 R$ would be associated with fibrosing alveolitis; however, no such association was observed. In contrast, a protective association of IL23R SNP with PHT was observed. It is important to note that PHT was not confirmed by rightheart catheterization in all patients unless this was deemed medically necessary by the practicing physician. These data suggest that $I L 23 R$ may help to identify a unique subset of patients with ATA-positive SSc who are at risk for developing PHT without interstitial lung disease.

Recently, a large number of studies have identified genes that are associated with development of multiple autoimmune diseases ${ }^{29,31,34-36}$. Results from these studies point to shared genes, often with functions involved in immune regulation, as risk factors for development of autoimmunity and, in turn, autoimmune diseases. For example, PTPN22 has been associated with development of type I diabetes mellitus, rheumatoid arthritis, systemic lupus erythematosus (SLE), and $\mathrm{SSc}^{31,34,35}$. IRF5, a susceptibility gene for SLE, has been associated with development of diffuse $\operatorname{SSc}^{29,36}$. Our report identifies $I L 23 R$ as a susceptibility factor for the ATA-positive subset of SSc. Other studies have shown that $I L 23 R$ SNP are associated with a group of immune-mediated illnesses commonly thought to share similar immune alterations, including IBD, psoriasis, and $\mathrm{AS}^{11-16,37}$. 
Table 5A. Distribution of the IL23R SNP rs11209026 genotype and alleles in North American Caucasian patients with SSc and healthy controls. Odds ratios (95\% CI) are for carriage of the minor allele.

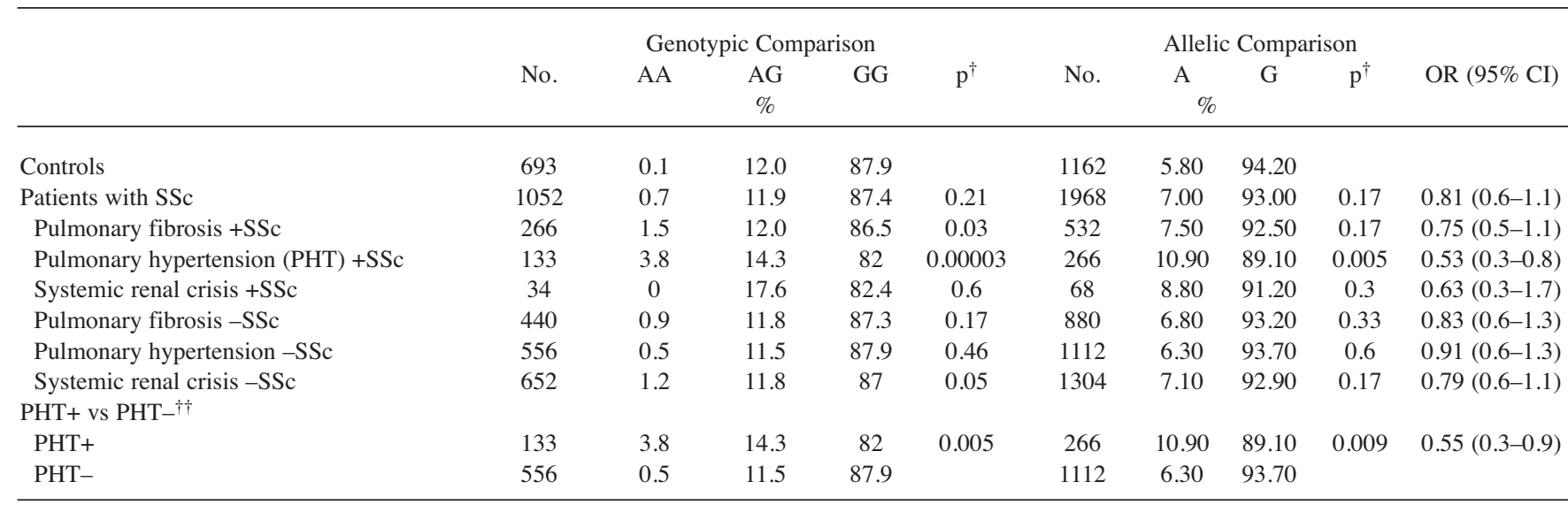

${ }^{\dagger} \mathrm{p}$ values considered significant after correcting for multiple comparisons using the false discovery method and point-wise significance $=0.0051 .{ }^{\dagger \dagger}$ Controls used as reference for all comparisons except this one.

Table 5B. Distribution of the IL23R SNP rs11465804 genotype and alleles in North American Caucasian patients with SSc and healthy controls. Odds ratios (95\% CI) are for carriage of the minor allele.

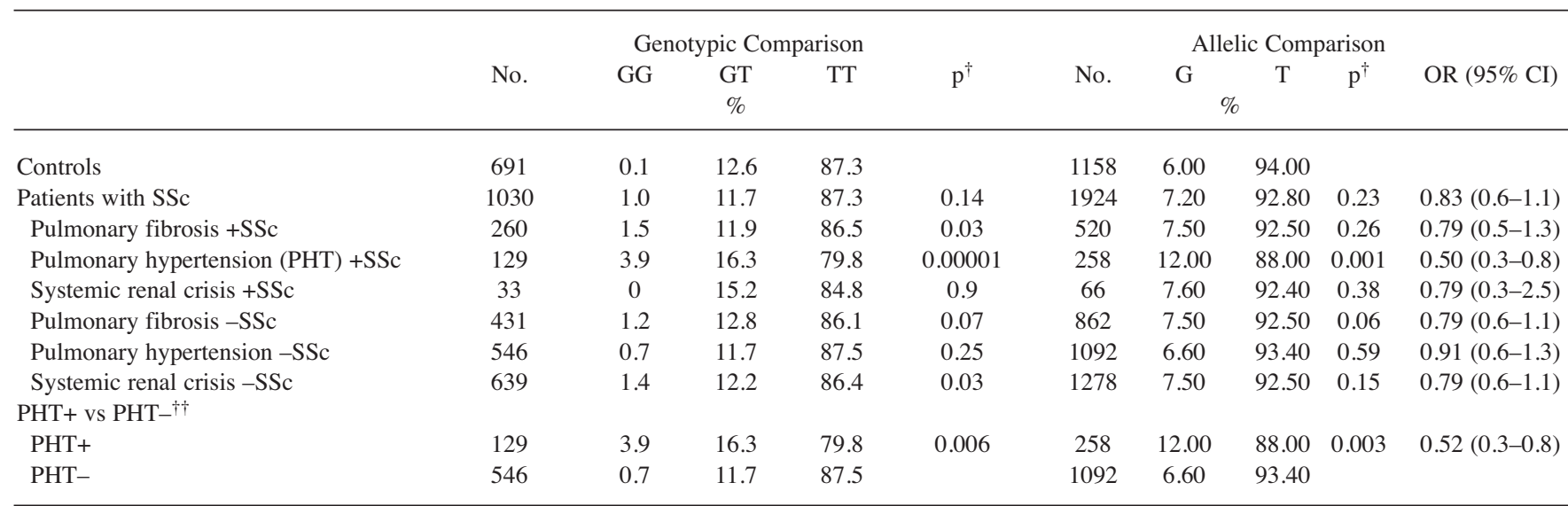

$\dagger \mathrm{p}$ values considered significant after correcting for multiple comparisons using the false discovery method and point-wise significance $=0.0051 .{ }^{\dagger \dagger}$ Controls used as reference for all comparisons except this one.

Together, these studies suggest that common biological pathways of immune dysregulation can lead to the development of a variety of autoimmune and inflammatory diseases, but are not able to explain why certain individuals preferentially develop one autoimmune disease over another. Investigation of how genetic variations regulate these biological pathways will improve our understanding of the pathogenesis of these complex polygenic disorders.

In contrast to our findings, it has been reported that IL23R SNP do not confer risk for development of SSc 38,39 . The factors responsible for these discrepant results could be differences in the IL23R SNP in each study, differences in the LD of $I L 23 R$ SNP in various populations, lack of power to detect the change due to smaller sample size, or variations in the minor allele frequencies between different ethnic groups based on the genetic drift and isolation of that ethnicity in their population history. In our study, Caucasian,
African American, and Hispanic populations showed associations of different $I L 23 R$ SNP with SSc. This suggests that there are differences in the IL23R SNP in these 3 cohorts, which might explain the lack of association in the Dutch and Spanish populations compared to our North American cohorts. Perhaps differences in the frequencies of clinical features and SSc-associated autoantibodies (ACA, ATA, ARA) among the 2 studies along with the small sample size of the former ${ }^{38}$ may be responsible for the lack of association. No clinical information on the SSc patients was reported in the Hungarian cohort ${ }^{39}$. The combined Dutch and Spanish cohorts comprised 518 SSc patients, but only 100 (19\%) were positive for ATA $^{38}$. Our cohort had a similar percentage of ATA-positive patients, but the total number of ATA-positive SSc patients was 256. As the association of $I L 23 R$ was found only in ATA-positive patients in our study, it is reasonable to postulate that the previous studies ${ }^{38,39}$ 
were not sufficiently powered to detect an association in the ATA-positive subset of SSc patients. Unfortunately, a metaanalysis of previous studies and the current report could not be performed because the allelic and genotypic frequencies of the clinical and autoantibody subsets of SSc were not described in those studies. Finally, the previous studies did not test for IL23R SNP associations with visceral involvement (e.g., PHT) in patients with SSc.

It has been hypothesized that Th17 cells might play a role in the pathogenesis of SSc. Indeed, plasma concentrations of IL-17 and IL-23 were reported to be elevated in Japanese patients with SSc from 2 cohorts ${ }^{17,18}$. Further, peripheral blood T cells from SSc patients have been reported to produce increased levels of IL-17 17 . These studies point to an increase in Th17 cytokine activity in SSc. The link between PHT and Th17 cells or IL-23 is less clear. Neither IL-17 nor IL-23 has been reported to be elevated in PHT. However, cytokines such as IL- 6 and TGF- $\beta$ that promote a Th17 response are increased in $\mathrm{PHT}^{40}$. There is some evidence to support the cross-regulation of IL-17/IL-23 and some of the molecular mediators of PHT such as nitric oxide, endothelin, and prostaglandin $\mathrm{E}_{2}$; however, this remains speculative ${ }^{41-43}$. Studies are needed to determine how the polymorphisms in the IL23R alter IL23R signaling and Th17 development and how this may relate to the pathogenesis of SSc and SSc-associated PHT.

Despite our large cohort (> 1400 SSc patients), our study is limited due to the absence of a replication cohort. Efforts are under way to determine if these SNP also are associated with SSc susceptibility in other populations. Our findings emphasize that these studies need to be sufficiently powered with ATA-positive patients, as IL23R SNP are not associated with ACA- or ARA-positive SSc. Another limitation of our study is that our findings are directly applicable to a North American Caucasian population. The ethnicity we reported was self-defined and the possibility of mixed populations within this group should be considered when interpreting these findings. We found no associations of IL23R SNP with subsets of SSc in African Americans or Hispanics or upon combination of the 3 cohorts by Mantel-Haenszel test. It is possible that there may be multiple SNP on the $I L 23 R$ gene involved in SSc susceptibility that are unique to each ethnic/regional population but are in LD with the undetected causal SNP. Higher resolution genotyping or DNA sequencing of the $I L 23 R$ gene would be required to identify the SNP involved in SSc pathogenesis, and to determine the variation in genetic structure of this gene in various populations.

We identified $I L 23 R$ as a susceptibility gene for development of ATA-positive SSc that is protective against the development of pulmonary hypertension. These data extend our understanding of the complex immunopathogenesis of SSc and provide support for a potential role of Th17 cells in the immunopathogenesis of SSc. The association of IL23R
SNP and ATA-positive SSc may have important implications in the identification of potential therapeutic targets in SSc.

\section{ACKNOWLEDGMENT}

We thank our patients and controls who participated in these cohorts, without whom these studies would not be possible.

\section{REFERENCES}

1. Charles C, Clements P, Furst DE. Systemic sclerosis: hypothesis-driven treatment strategies. Lancet 2006;367:1683-91.

2. Fleischmajer R, Perlish JS, Reeves JR. Cellular infiltrates in scleroderma skin. Arthritis Rheum 1977;20:975-84.

3. Mosmann TR, Sad S. The expanding universe of T-cell subsets: Th1, Th2 and more. Immunol Today 1996;17:138-46.

4. Mosmann TR, Cherwinski H, Bond MW, Giedlin MA, Coffman RL. Two types of murine helper T cell clone. I. Definition according to profiles of lymphokine activities and secreted proteins J Immunol 2005;175:5-14.

5. Harrington LE, Hatton RD, Mangan PR, Turner H, Murphy TL, Murphy KM, et al. Interleukin 17-producing CD4+ effector T cells develop via a lineage distinct from the T helper type 1 and 2 lineages. Nat Immunol 2005;6:1123-32.

6. Veldhoen M, Stockinger B. TGF beta 1, a "Jack of all trades": the link with pro-inflammatory IL-17-producing T cells. Trends Immunol 2006;27:358-61.

7. Veldhoen M, Hocking RJ, Atkins CJ, Locksley RM, Stockinger B TGF beta in the context of an inflammatory cytokine milieu supports de novo differentiation of IL-17-producing T cells. Immunity 2006;24:179-89.

8. Oukka M. Th17 cells in immunity and autoimmunity. Ann Rheum Dis 2008;67 Suppl 3:iii26-iii29.

9. Cua DJ, Sherlock J, Chen Y, Murphy CA, Joyce B, Seymour B, et al. Interleukin-23 rather than interleukin-12 is the critical cytokine for autoimmune inflammation of the brain. Nature 2003;421:744-8.

10. Bettelli E, Korn T, Kuchroo VK. Th17: the third member of the effector T cell trilogy. Curr Opin Immunol 2007;19:652-7.

11. Duerr RH, Taylor KD, Brant SR, Rioux JD, Silverberg MS, Daly $\mathrm{MJ}$, et al. A genome-wide association study identifies IL23R as an inflammatory bowel disease gene. Science 2006;314:1461-3.

12. Franke A, Balschun T, Karlsen TH, Sventoraityte J, Nikolaus S, Mayr G, et al. Sequence variants in IL10, ARPC2 and multiple other loci contribute to ulcerative colitis susceptibility. Nat Genet 2008;40:1319-23.

13. Burton PR, Clayton DG, Cardon LR, Craddock N, Deloukas P, Duncanson A, et al. Association scan of 14,500 nonsynonymous SNPs in four diseases identifies autoimmunity variants. Nat Genet 2007;39:1329-37.

14. Nair RP, Duffin KC, Helms C, Ding J, Stuart PE, Goldgar D, et al. Genome-wide scan reveals association of psoriasis with IL-23 and NF-kappa B pathways. Nat Genet 2009;41:199-204.

15. Rahman P, Inman RD, Maksymowych WP, Reeve JP, Peddle L, Gladman DD. Association of interleukin 23 receptor variants with psoriatic arthritis. J Rheumatol 2009;36:137-40.

16. Rahman P, Inman RD, Gladman DD, Reeve JP, Peddle L, Maksymowych WP. Association of interleukin-23 receptor variants with ankylosing spondylitis. Arthritis Rheum 2008;58:1020-5.

17. Kurasawa K, Hirose K, Sano H, Endo H, Shinkai H, Nawata Y, et al. Increased interleukin-17 production in patients with systemic sclerosis. Arthritis Rheum 2000;43:2455-63.

18. Komura K, Fujimoto M, Hasegawa M, Ogawa F, Hara T, Muroi E, et al. Increased serum interleukin 23 in patients with systemic sclerosis. J Rheumatol 2008;35:120-5.

19. Mayes MD. The establishment and utility of a population-based registry to understand the epidemiology of systemic sclerosis. Curr 
Rheumatol Rep 2000;2:512-6.

20. Arnett FC, Reveille JD, Goldstein R, Pollard KM, Leaird K, Smith EA, et al. Autoantibodies to fibrillarin in systemic sclerosis (scleroderma). An immunogenetic, serologic, and clinical analysis. Arthritis Rheum 1996;39:1151-60.

21. Reveille JD, Fischbach M, McNearney T, Friedman AW, Aguilar MB, Lisse J, et al. Systemic sclerosis in 3 US ethnic groups: a comparison of clinical, sociodemographic, serologic, and immunogenetic determinants. Semin Arthritis Rheum 2001; 30:332-46.

22. Preliminary criteria for the classification of systemic sclerosis (scleroderma). Subcommittee for scleroderma criteria of the American Rheumatism Association Diagnostic and Therapeutic Criteria Committee. Arthritis Rheum 1980;23:581-90.

23. Assassi S, Arnett FC, Reveille JD, Gourh P, Mayes MD. Clinical, immunologic, and genetic features of familial systemic sclerosis. Arthritis Rheum 2007;56:2031-7.

24. Hummers LK, Hall A, Wigley FM, Simons M. Abnormalities in the regulators of angiogenesis in patients with scleroderma. J Rheumatol 2009;36:576-82.

25. LeRoy EC, Black C, Fleischmajer R, Jablonska S, Krieg T, Medsger TA Jr, et al. Scleroderma (systemic sclerosis): classification, subsets and pathogenesis. J Rheumatol 1988; 15:202-5.

26. Fritzler MJ, Kinsella TD. The CREST syndrome: a distinct serologic entity with anticentromere antibodies. Am J Med 1980;69:520-6

27. Benjamini Y, Hochberg Y. Controlling the false discovery rate: a practical and powerful approach to multiple testing. J Roy Statist Soc 1995;57:289-300.

28. Meyer OC, Fertig N, Lucas M, Somogyi N, Medsger TA Jr. Disease subsets, antinuclear antibody profile, and clinical features in 127 French and 247 US adult patients with systemic sclerosis. J Rheumatol 2007;34:104-9.

29. Dieude P, Guedj M, Wipff J, Avouac J, Fajardy I, Diot E, et al Association between the IRF5 rs2004640 functional polymorphism and systemic sclerosis: a new perspective for pulmonary fibrosis. Arthritis Rheum 2009;60:225-33.

30. Alkassab F, Gourh P, Tan FK, McNearney T, Fischbach M, Ahn C, et al. An allograft inflammatory factor 1 (AIF1) single nucleotide polymorphism (SNP) is associated with anticentromere antibody positive systemic sclerosis. Rheumatology 2007;46:1248-51.

31. Gourh P, Tan FK, Assassi S, Ahn CW, McNearney TA, Fischbach $\mathrm{M}$, et al. Association of the PTPN22 R620W polymorphism with anti-topoisomerase I- and anticentromere antibody-positive systemic sclerosis. Arthritis Rheum 2006;54:3945-53.
32. Reveille JD, Durban E, MacLeod-St. Clair MJ, Goldstein R, Moreda R, Altman RD, et al. Association of amino acid sequences in the HLA-DQB1 first domain with antitopoisomerase I autoantibody response in scleroderma (progressive systemic sclerosis).

J Clin Invest 1992;90:973-80.

33. Steen VD, Powell DL, Medsger TA Jr. Clinical correlations and prognosis based on serum autoantibodies in patients with systemic sclerosis. Arthritis Rheum 1988;31:196-203.

34. Begovich AB, Carlton VE, Honigberg LA, Schrodi SJ, Chokkalingam AP, Alexander HC, et al. A missense single-nucleotide polymorphism in a gene encoding a protein tyrosine phosphatase (PTPN22) is associated with rheumatoid arthritis. Am J Hum Genet 2004;75:330-7.

35. Onengut-Gumuscu S, Ewens KG, Spielman RS, Concannon P. A functional polymorphism $(1858 \mathrm{C} / \mathrm{T})$ in the PTPN22 gene is linked and associated with type I diabetes in multiplex families. Genes Immun 2004;5:678-80.

36. Graham RR, Kyogoku C, Sigurdsson S, Vlasova IA, Davies LR, Baechler EC, et al. Three functional variants of IFN regulatory factor 5 (IRF5) define risk and protective haplotypes for human lupus. Proc Natl Acad Sci USA 2007;104:6758-63.

37. Nair RP, Ruether A, Stuart PE, Jenisch S, Tejasvi T, Hiremagalore $\mathrm{R}$, et al. Polymorphisms of the IL12B and IL23R genes are associated with psoriasis. J Invest Dermatol 2008;128:1653-61.

38. Rueda B, Broen J, Torres O, Simeon C, Ortego-Centeno N, Schrijvenaars MM, et al. The interleukin 23 receptor gene does not confer risk to systemic sclerosis and is not associated with systemic sclerosis disease phenotype. Ann Rheum Dis 2009;68:253-6.

39. Farago B, Magyari L, Safrany E, Csongei V, Jaromi L, Horvatovich $\mathrm{K}$, et al. Functional variants of interleukin-23 receptor gene confer risk for rheumatoid arthritis but not for systemic sclerosis. Ann Rheum Dis 2008;67:248-50.

40. Tuder RM, Marecki JC, Richter A, Fijalkowska I, Flores S. Pathology of pulmonary hypertension. Clin Chest Med 2007; 28:23-42, vii.

41. Hao JS, Shan BE. Immune enhancement and anti-tumour activity of IL-23. Cancer Immunol Immunother 2006;55:1426-31.

42. Chizzolini C, Chicheportiche R, Alvarez M, de RC, Roux-Lombard P, Ferrari-Lacraz S, et al. Prostaglandin E2 synergistically with interleukin-23 favors human Th17 expansion. Blood 2008;112:3696-703.

43. LeGrand A, Fermor B, Fink C, Pisetsky DS, Weinberg JB, Vail TP, et al. Interleukin-1, tumor necrosis factor alpha, and interleukin-17 synergistically up-regulate nitric oxide and prostaglandin E2 production in explants of human osteoarthritic knee menisci. Arthritis Rheum 2001;44:2078-83. 